\section{O universal e o particular na função filtro do médico geral}

\section{The universal and the specific in the filter function of the general practitioner}

\section{Paulo Eduardo Margeon Elias}

Departamento de Medicina Preventiva da Faculdade de Medicina da USP

Correspondência: Av. Dr. Arnaldo, 455 - 2ª andar - Cerqueira Cesar - 01246-903 São Paulo - SP. E-mail:pemelias@usp.br
$\mathrm{O}$ artigo de autoria do renomado especialista Juan Gérvas e de Mercedes Perez Fernandes aborda aspecto dos mais relevantes para o aprofundamento do conhecimento sobre as intrincadas relações que se estabelecem entre os serviços de saúde e os níveis de atenção. Se o papel do médico geral vis a vis ao do especialista nos serviços de saúde hierarquizados por níveis de atenção constitui tema relativamente novo na produção científica nos países com tradição nesta área, em nosso meio não existem praticamente estudos produzidos com este enfoque, o que distingue o pioneirismo da Revista Brasileira de Epidemiologia ao promover este debate. A inexistência entre nós brasileiros desse tipo de produção talvez se explique pelos obstáculos em se obter as informações mais sofisticadas sobre a atenção primária nos sistemas de informação em saúde disponíveis, como também pelas dificuldades enfrentadas para se efetivar a organização de serviços de saúde em bases de níveis de atenção.

Inicialmente manifesto enorme simpatia pela tese defendida pelos autores, isto é, pelas vantagens relativas e absolutas da existência da função de filtro do médico geral por referência à atividade do especialista. Como demonstra o presente artigo, esta função de filtro se revela de grande valia para países capitalistas centrais que apresentam sistemas de saúde bem consolidados e com adequados aportes de recursos materiais e financeiros. No caso dos países da periferia do capitalismo, tornase ainda mais relevante esta função, na medida em que é ainda mais crucial a busca pela melhoria da eficácia social na produção dos serviços de saúde.

No entanto, como apontam os próprios autores, este artigo contempla várias indagações e à guisa do debate apresento duas ordens de questões suscitadas pela leitura e a seguir apresentadas.

A primeira delas, na falta de termo mais preciso nomeio de pretensão ao universal da função filtro do médico geral. A indagação já me foi sugerida desde o título do ar- 
tigo ao enfatizar o fundamento científico desta função do médico geral. À primeira vista este apelo ao científico me sugeriu muito mais o acento de um status universal para o objeto do estudo, a função filtro do médico geral, do que propriamente os parâmetros de sua construção, sensação intensamente reforçada ao término da leitura. Trata-se essencialmente da abordagem do tema, praticamente desvinculandoo dos sentidos e objetivos dos sistemas de saúde em que se inserem, e também da cultura institucional dos serviços de saúde nos quais se efetivam. Mais precisamente, pretendo sustentar que o desempenho da função filtro do médico geral enquanto ação social depende em ultima instância das políticas de saúde que engendram determinados arranjos na organização dos serviços de saúde e propiciam o estabelecimento de culturas institucionais que, ao lado do nível de consciência sanitária da população, conformam particularidades aos sistemas e serviços de saúde de cada país. Desta maneira, penso ser a política que confere sentido de devir à função filtro do médico geral, em termos de colocar em foco as finalidades desta ação, suscitando indagações tais como para quê e para quem se destinam. Ao sugerir a concepção da função filtro por este prisma, pretendo ressaltar sua dependência de outras esferas sociais, ao mesmo tempo em que assinalo as particularidades que sujeitam esta ação em diferentes países e mesmo em distintas regiões de cada país.

Com tal postulação não pretendo negar existência a uma dimensão universal para a função filtro do médico geral, com elementos comuns encontráveis em diferentes sistemas de saúde, como aliás fundamenta o artigo em tela, mas apenas apontar a essencialidade da dimensão particularista na efetivação desta ação e a necessidade de referi-la aos sistemas de saúde.

Starfield, em sua famosa obra, ao abordar a capacidade-desempenho da atenção primária o faz propondo uma série de elementos dentre os quais a acessibilidade, a variedade de serviços, a utilização e o reconhecimento de um problema ou necessidade que conseguem abarcar aspectos universais e particulares do funcionamento deste nível de atenção. De maneira análoga, suponho que seria mais produtiva e precisa uma abordagem da função filtro do médico geral que pudesse agregar elementos aos já apresentados pelos autores. Assim, aos aspectos citados, tais como o filtro pessoal e o familiar, a concatenação do trabalho do médico geral e do especialista, poderia se juntar um tópico dedicado aos sistemas de saúde, com especial ênfase aos arranjos engendrados para a organização de serviços, a cultura institucional neles prevalecentes e a consciência sanitária da população.

A segunda questão, de certo modo conexa à primeira, diz respeito aos pressupostos para a consecução da função filtro pelo médico geral e os meios técnicooperacionais necessários para a realização desta ação.

Dentre os pressupostos vale retomar pelo menos os elementos classificados por Starfield como estruturais ${ }^{1}$, sem os quais a função filtro do médico geral resulta bastante comprometida em termos de sua eficácia social. Deste modo, a mesma precisão utilizada no artigo ao tratar das relações de dependência entre efeitos e resultados das provas diagnósticas deveria se estender à abordagem dos pressupostos necessários à função filtro do médico geral. Em relação aos meios técnico-operacionais, para além da capacitação e atualização de conhecimentos do médico geral, refiro-me a seu acesso aos meios requeridos para a realização do diagnóstico no nível de atenção primária, ou seja, pelo menos a disposição de laboratório clínico e de serviço de radiologia e imagens. Tal menção pode parecer descabida aos olhos de um leitor de paises do capitalismo cen-

1 São eles a acessibilidade, a variedade de serviços, a definição da população eletiva e a continuidade. 
tral, mas para os países da periferia não o é se considerada a situação efetiva de trabalho da maioria dos médicos vinculados à atenção primária, mesmo nas regiões economicamente mais desenvolvidas, como ilustra no Brasil a situação da região metropolitana de S. Paulo.

Cabe ainda mencionar rapidamente a adequação de perfil do profissional para realizar a função filtro na atenção primária: se o médico geral, como defendem os autores, ou o médico de família e comunidade. Este último parece ter como vantagem a formação especializada realizada em serviços com ampla atuação comunitária e a abordagem da família, o que, pelo menos em tese, melhor o habilitaria a considerar os aspectos culturais e os sociais envolvidos na ação assistencial que poderia resultar em melhor desempenho na função filtro do nível primário.
Finalizando, sensibilizado pela excelência do artigo, ouso lançar uma espécie de agenda desafio para a pesquisa neste tema: a elaboração de protocolos para a realização de estudos comparativos sobre a função filtro do médico na atenção primária, abrangendo sistemas de saúde dos países centrais e dos periféricos, e em cada um deles a avaliação de desempenho entre os médicos gerais e os de família e comunidade. Talvez tais estudos nos permitam enxergar com mais nitidez os elementos universais e os particulares envolvidos na função filtro do médico em sistemas de saúde de países bastante diversos. Por seu lado, esta identificação poderia fornecer subsídios para a adoção da função filtro com vistas à melhoria da assistência à população, objetivo último que deveria estar presente em qualquer sistema de saúde.

\section{Referências}

1. Acurcio FA et al. Analysis of medical prescriptions despensed at health centers in Belo Horizonte, Minas Gerais, Brazil. Cad Saúde Pública 2004; 20(1): 72-9.

2. Bousquat A, Cohn A, Elias PE. O PSF e a dinâmica urbana das grandes cidades. In: Viana AL, Elias PE, Ibanez N. Proteção Social: dilemas e desafios. S. Paulo: Hucitec; 2005.

3. Gusso G. Atención Primaria de Salud em Brasil: passado reciente y retos. SEMERGEN 2004; 30(8):408-10.

4. Mendes EV. Uma agenda para a saúde. São Paulo: Hucitec; 1996.
5. Samaja J. A reprodução social e a saúde: elementos metodológicos sobre a questão das relações entre saúde e condições de vida. Salvador: Casa da Qualidade Editora; 2000 .

6. Starfield B. Atenção primária: equilíbrio entre necessidades de saúde, serviços e tecnologia ( $2^{\mathrm{a}} \mathrm{Ed}$.). Brasília: UNESCO Brasil, Ministério da Saúde; 2004. [Edição publicada em inglês em 1998.]

7. Viana AL, Lima LD, Oliveira RG. Descentralização e federalismo: a política de saúde em novo contexto lições do caso brasileiro. Ciênc Saúde Coletiva 2002: 7(3): 493-507. 